\title{
Encoding of emotion-paired spatial stimuli in the rodent hippocampus
}

\author{
Rebecca Nalloor ${ }^{1,2}$, Kristopher M. Bunting ${ }^{1}$ and Almira Vazdarjanova ${ }^{1,2 *}$ \\ Brain and Behavior Discovery Institute and Department of Neurology, Georgia Health Sciences University, Augusta, GA, USA \\ 2 School of Graduate Studies, Georgia Health Sciences University, Augusta, GA, USA
}

\author{
Edited by: \\ Antonella Gasbarri, University of \\ L'Aquila, Italy \\ Reviewed by: \\ Barry Setlow, University of Florida, \\ USA \\ Christa Mclntyre, University of \\ Texas, USA \\ Sara N. Burke, University of \\ Arizona - NSMA, USA \\ *Correspondence: \\ Almira Vazdarjanova, Brain and \\ Behavior Discovery Institute and \\ Department of Neurology, Georgia \\ Health Sciences University, \\ 1120 15th Street, Augusta, \\ GA 30912, USA. \\ e-mail: avazdarjanova@ \\ georgiahealth.edu
}

Rats can acquire the cognitive component of CS-US associations between sensory and aversive stimuli without a functional basolateral amygdala (BLA). Thus, other brain regions should support such associations. Some septal/dorsal CA1 (dCA1) neurons respond to both spatial stimuli and footshock, suggesting that dCA1 could be one such region. We report that, in both dorsal and ventral hippocampus, different neuronal ensembles express immediate-early genes (IEGs) when a place is experienced alone vs. when it is associated with foot shock. We assessed changes in the size and overlap of hippocampal neuronal ensembles activated by two behavioral events using a cellular imaging method, Arc/Homer1a catFISH. The control group (A-A) experienced the same place twice, while the experimental group (A-CFC) received the same training plus two foot shocks during the second event. During fear conditioning, A-CFC, compared to A-A, rats had a smaller ensemble size in $\mathrm{dCA} 3, \mathrm{dCA} 1$, and $\mathrm{vCA} 3$, but not $\mathrm{vCA} 1$. Additionally, A-CFC rats had a lower overlap score in dCA1 and vCA3. Locomotion did not correlate with ensemble size. Importantly, foot shocks delivered in a training paradigm that prevents establishing shock-context associations, did not induce significant Arc expression, rejecting the possibility that the observed changes in ensemble size and composition simply reflect experiencing a foot shock. Combined with data that Arc is necessary for lasting synaptic plasticity and long-term memory, the data suggests that Arc/H1a+ hippocampal neuronal ensembles encode aspects of fear conditioning beyond space and time. Rats, like humans, may use the hippocampus to create integrated episodic-like memory during fear conditioning.

\footnotetext{
Keywords: Arc, Homer 1a, fear conditioning, emotional memory, ventral CA1, ventral CA3, catFISH, dorsal hippocampus
}

\section{INTRODUCTION}

Forming associations between neutral and aversive stimuli is essential for survival. Such learning can be conceptualized in classical conditioning terms as forming CS-US associations, where a conditioned stimulus (CS) comes to elicit conditioned emotional responses only after being paired with an unconditioned stimulus (US), which elicits unconditioned emotional responses before the pairing (Pavlov, 1927). Although experimentally, responses are measured and used to assess the strength of associations, classical conditioning training elicits at least two types of learning: forming stimulus-response (S-R) associations and forming stimulus-stimulus (S-S) associations.

Conceptually, the existence of what is now known as "stimulus-stimulus associations" was postulated by Tolman (Tolman, 1949). It is revealed by latent learning and sensory preconditioning, and has been demonstrated for contextual fear conditioning (Tolman, 1949; Vazdarjanova and McGaugh, 1998; O'Brien and Sutherland, 2007; Li et al., 2011). Associations between emotional and sensory stimuli can be assessed by measuring behaviors that are supported by such associations, but which were not conditioned during the training. Rats can flexibly express an acquired association between a shock and a place, independent from any reinforced responses during the training. When rats with pre- or post-training lesions of the basolateral amygdala (BLA) are confined to one context during training and receive an aversive stimulus (contextual fear conditioning), but are allowed to make a choice between this context over a context where they have not received foot shocks during testing, they avoid the footshock-associated context, even when they show little freezing (Vazdarjanova and McGaugh, 1998, 1999). Therefore, structures other than the BLA must support the flexible expression of footshock-place associations.

Flexible expression of stimulus-stimulus associations is a hallmark of episodic-like memories which are known to exist in nonhuman animals, and to rely on associating "what," "where" and "when" of an experience (Clayton and Dickinson, 1998; Morris, 2001; Babb and Crystal, 2006; Ferbinteanu et al., 2006; KartTeke et al., 2006; Clayton et al., 2007; Eichenbaum et al., 2011). Such associations are supported by the hippocampus (Morris, 2001; Bast et al., 2005; Li and Chao, 2008; Sauvage et al., 2008), likely in conjunction with closely related structures, such as the entorhinal and perirhinal cortex, as well as the BLA and prefrontal 
cortex. In humans, S-S associations for emotional stimuli during classical conditioning depend on the hippocampus (Bechara et al., 1995) and are modulated by the amygdala (Cahill and McGaugh, 1998). In animals, episodic-like memories have been demonstrated during fear conditioning (O'Brien and Sutherland, 2007). Fear conditioning also changes the firing characteristics and "place fields" of dCA1 cells (Moita et al., 2004; Chen et al., 2009). Whether the reported transient firing is sufficient to induce molecular changes that support long-term memory, or whether such changes are intrinsic to the dCA1 is unknown. Furthermore, it is unknown whether the ventral/temporal, compared to the dorsal/septal, part of the hippocampus preferentially contributes to such changes. Due to its connectivity, distinct gene expression patterns, and evidence from lesion and pharmacological studies, the ventral hippocampus has been associated with the temporal lobe system which regulates motivational and emotional behavior, while the dorsal hippocampus has been associated with navigation and exploration (reviewed in Fanselow and Dong, 2010; Bast, 2011). Therefore, we investigated whether changes during fear conditioning, independent of spatial cues, are encoded by the CA1 and CA3 hippocampal regions and whether they are more pronounced in the ventral, as compared to the dorsal, hippocampus.

We assessed large neuronal ensembles from the dorsal and ventral parts of the CA1 and CA3 regions of the hippocampus using a cellular imaging method which examines plasticity-related immediate-early gene (IEG) expression: Arc/H1a catFISH (cellular compartment analysis of temporal activity by fluorescence in-situ hybridization using Arc and Homer 1a) (Vazdarjanova et al., 2002). Arc/Arg3.1 (activity-regulated cytoskeleton-associated protein) and Homerla (H1a) are effector IEGs that are coordinately expressed during behavior (Vazdarjanova et al., 2002) and are useful markers of plasticity. The proteins they encode are targeted to, or synthesized at, activated dendrites, where they participate in establishing structural and functional changes that support homeostatic scaling, long-term synaptic plasticity, and long-term memory (reviewed in Fagni et al., 2002; Szumlinski et al., 2006; Bramham et al., 2010). Importantly, Arc expression can be dissociated from activity and predicts the pattern of plasticity assessed electrophysiologically one day later (Guzowski et al., 2006; Carpenter-Hyland et al., 2010).

The Arc/H1a catFISH method is a powerful tool that can detect differences in the size and overlap of large neuronal ensembles, which have initiated expression of Arc/Arg3.1 and Homer1a during two temporally separate behavioral episodes, across multiple brain regions in the same animals. Due to the brief period of transcription ( $<10 \mathrm{~min}$ ) of these genes and the differences in size between their primary transcripts, H1a intranuclear foci of transcription mark cells that initiated transcription 25-35 min before the animal's death, while those with Arc foci mark cells with transcription initiated 2-12 min before death (Guzowski et al., 1999; Vazdarjanova et al., 2002). Using this method it has been shown that exploring the same place twice induces Arc/H1a expression in largely overlapping dCA1 neuronal ensembles (Guzowski et al., 1999; Vazdarjanova et al., 2002; Vazdarjanova and Guzowski, 2004; Ramírez-Amaya et al., 2005), similar to findings from electrophysiological studies of "place cells" (McNaughton et al., 1989;
Barnes et al., 1990; Lee et al., 2004; Leutgeb et al., 2004). Here we show that both the size and overlap of hippocampal IEGexpressing neuronal ensembles is decreased by fear conditioning, compared to experiencing the same place with the same spatial features and relationships. We also show that the changes vary between CA3 and CA1 and along the septo-temporal axis of the hippocampus.

\section{MATERIALS AND METHODS SUBJECTS}

Young adult (250-300 g) male Sprague-Dawley rats (Charles Rivers Laboratories Inc., MA) were double housed on a $12 \mathrm{~h}$ light/dark cycle (lights on at 7:00 am) with food and water freely available. All testing was performed between 9:00 am and 5:00 pm.

\section{BEHAVIORAL PROCEDURES}

All behavioral procedures were approved by the Institutional Animal Care and Use Committee (IACUC), Georgia Health Sciences University, Augusta, GA. All analyses were performed by an experimenter unaware of the group assignment of each rat.

\section{EXPERIMENTAL DESIGN}

The experimental design is summarized in Figure 1A. A-A animals $(n=6)$ were subjected to two emotionally neutral (no shock) explorations of a $50 \times 10 \times 19 \mathrm{~cm}$ box, made of two stainless steel plates separated at the floor with a $1 \mathrm{~cm}$ gap. The two, $5 \mathrm{~min}$ explorations were separated by a $20 \mathrm{~min}$ rest period in the home cage. The A-CFC animals $(n=6)$ received

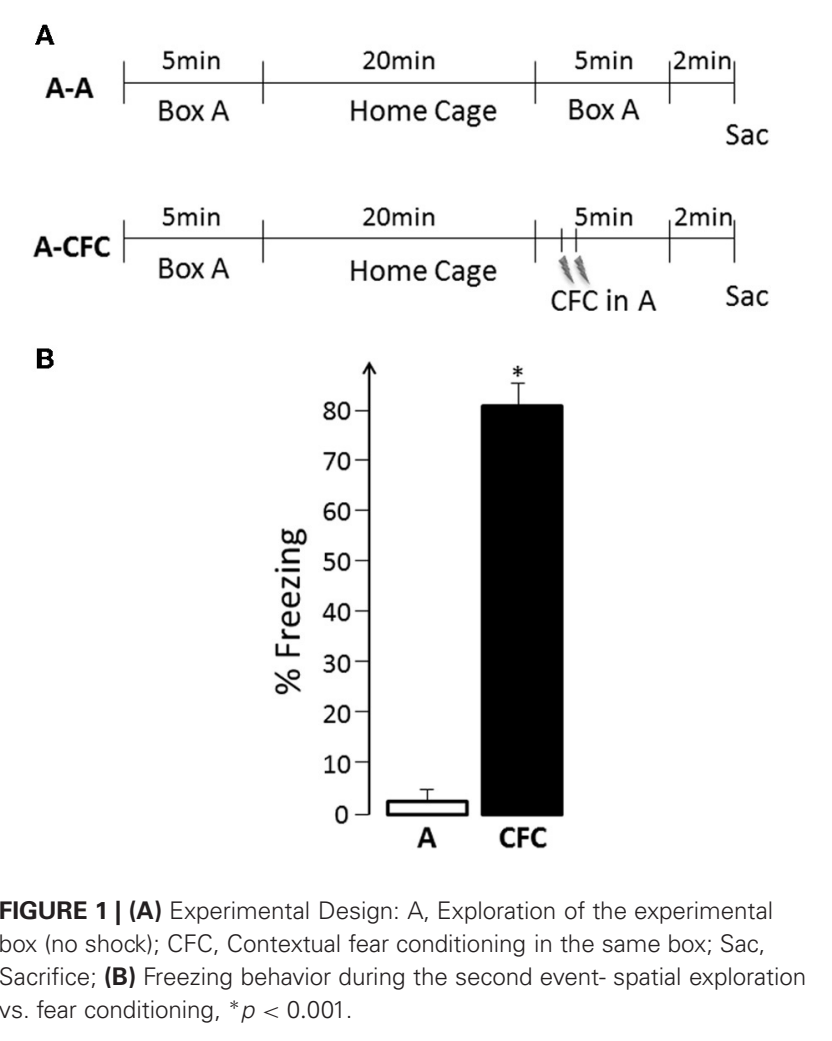


identical treatment, except that during the second exploration they received two foot shocks administered through the stainless steel plates $(1 \mathrm{~mA} \mathrm{AC,} 1 \mathrm{~s}, 30 \mathrm{~s}$ apart, first shock $1 \mathrm{~min}$ into the session). An additional 12 rats received either CFC training or spatial exploration and, $24 \mathrm{~h}$ later, were placed in the apparatus for $5 \mathrm{~min}$ to assess long-term memory of the training. No foot shocks were administered during the testing. All behavior was recorded using an overhead camera. Fear behavior was measured as time spent freezing, which was scored as lack of movement except that needed for respiration. A crossing was scored when a rat was moving through the apparatus and the base of the tail crossed the midpoint of the apparatus. To assess the percentage of cells with IEG expression in response solely to foot shock, three rats were introduced to the apparatus, immediately shocked for $2 \mathrm{~s}$, and then promptly removed and anesthetized with isoflurane to prevent IEG expression due to subsequent exploratory behavior that is usually seen with such "immediate shock" treatment. These rats were maintained under general anesthesia for $5 \mathrm{~min}$ to allow footshock-initiated transcription to proceed, and then the brain was harvested. Three more rats were used as "cage controls." They were taken directly from their cage, anesthetized and the brains were harvested.

\section{BRAIN HARVESTING AND SECTIONING}

At the end of each experiment, the animals were decapitated using a rat guillotine, the brain rapidly harvested, flash-frozen in isopentane, and stored at $-80^{\circ} \mathrm{C}$. Right hemispheres of brains from different conditions were blocked together in freezing medium such that several behavioral groups were represented in each block. Twenty micron thick coronal sections were cut on a cryostat and mounted on glass slides. The slides were stored at $-20^{\circ} \mathrm{C}$ until further processing.

\section{Arc/H1a catFISH}

Slides were processed for double Arc/H1a in situ hybridization as described previously (Vazdarjanova and Guzowski, 2004). Briefly, after fixing and permeabilizing the tissue, a fluorescein-labeled full-length Arc antisense riboprobe and digoxigenin-labeled $\mathrm{H} 1 \mathrm{a}$ antisense riboprobe, targeting the $3^{\prime}$ UTR of $H 1 a$ mRNA, were applied and hybridized overnight at $56^{\circ} \mathrm{C}$. Following quenching of peroxidase activity, the fluorescein tag was revealed with peroxidase-conjugated anti-fluorescein antibody (Fab fragments, Roche, Indianapolis, IN) and a tyramide amplification reaction with either fluorescein or cyanine 3 (SuperGlo ${ }^{\mathrm{TM}}$ Green and SuperGlo ${ }^{\mathrm{TM}}$ Red, Fluorescent Solutions, Augusta, GA); these steps were repeated using peroxidase-conjugated anti-digoxigenin antibody (Fab fragments, Roche, Indianapolis, IN). Riboprobes were generated using MaxiScript (Ambion, Austin, TX) and AmpliScribe (Epicentre Biotechnologies, Madison, WI) in vitro transcription kits and fluorescein- and digoxigenin-labeled UTP (Roche). Nuclei were counterstained with DAPI.

\section{IMAGE ACQUISITION AND STEREOLOGICAL ANALYSIS}

Image stacks from the selected regions $(2.8-3.8 \mathrm{~mm}$ and $4.8-6.4 \mathrm{~mm}$ posterior to bregma for dorsal and ventral hippocampus, respectively) were collected from at least four different slides per animal with a $20 \times$ objective on a Zeiss
AxioImager/Apotome system. For the dCA3 region, mosaic images of CA3b were collected and analyzed. The position of the dCA1, vCA1, and vCA3 are illustrated in Figures $2 A$ and D. The choice of imaging fields from the ventral hippocampus was based on the projection patterns of the BLA (Pikkarainen et al., 1999; Petrovich et al., 2001).

Unbiased stereological cell counting and classification were performed as follows: (1) neurons were first segmented from the appropriate regions of interest; (2) segmented neurons were classified manually using AxioVision imaging software (Zeiss). Putative glial cells, those with small, intensely, and uniformly stained nuclei, were excluded from the analysis. Neuron-like cells in the regions of interest were counted by using an optical dissector method which minimizes sampling errors attributable to partial cells and stereological concerns (West et al., 1991). Cells were classified as Arc +, H1a+, or Arc/H1a+ depending on whether they had foci of transcription for Arc, H1a, or both, respectively. Those cells that lacked foci were classified as negative. Overlap scores were calculated as: $\left(\% \mathrm{Arc} / \mathrm{Hla}+\left(\% \mathrm{E}_{1} \times \% \mathrm{E}_{2}\right) / 100\right) /\left(\% \mathrm{E}_{\min }-\left(\% \mathrm{E}_{1} \times\right.\right.$ $\left.\left.\% \mathrm{E}_{2}\right) / 100\right)$, where $\% \mathrm{Arc} / \mathrm{H} 1 \mathrm{a}+=$ percentage of total neurons that are $\mathrm{Arc} / \mathrm{H} 1 \mathrm{a}+; \% \mathrm{E}_{1}=$ percentage of cells activated in the first behavioral event $=(H 1 a++A r c / H 1 a+) /$ total neurons; $\% \mathrm{E}_{2}=$ percentage of cells activated in the second behavioral event $=$ $(A r c++A r c / H 1 a+) /$ total neurons; $\left(\% \mathrm{E}_{1} \times \% \mathrm{E}_{2}\right) / 100=$ theoretical probability of cells activated during both events, assuming the two events activated independent groups of neurons; $\% \mathrm{E}_{\min }=$ lesser of $\% \mathrm{E}_{1}$ and $\% \mathrm{E}_{2}$, which normalizes the equation to a condition with a perfect overlap even if one population is smaller than the other. The Overlap Score is 1 for a perfect overlap $\left(\% \mathrm{E}_{1}=\% \mathrm{E}_{2}\right)$, and is 0 for two statistically independent $\% \mathrm{E}_{1}$ and $\% \mathrm{E}_{2}$. For purposes of clarity we refer to all $\mathrm{H} 1 \mathrm{a}+$ and Arc/H1a+ cells as an "ensemble" that activated IEG expression during the first event, and all Arc+ and Arc/H1a+ cells as an ensemble that activated IEG expression during the second event.

\section{STATISTICAL ANALYSES}

Time spent freezing, number of crossings, and overlap scores in the control and experimental groups were compared using analysis of variance (ANOVA). Ensemble size activated by the different events within the same control and experimental animals was analyzed using repeated measures ANOVA with Event and Group as the independent variables and ensemble size as the dependent variable. Statistically significant main effects were followed up by Fisher's PLSD post-hoc tests for four a-priori set comparisons: Event 1 vs. Event 2 for the A-A and A-CFC groups and A-A vs. A-CFC for Event 1 and Event 2. Correlation of ensemble size between regions was analyzed with simple regression analyses (StatView software, SAS Institute). Differences were considered statistically significant at $p<0.05$.

\section{RESULTS \\ FOOT SHOCK DURING A SECOND VISIT TO A NEW PLACE INDUCED FEAR CONDITIONING}

The experimental design is illustrated in Figure 1A. During the first exposure to the training apparatus, all rats displayed active exploration (mean of 11 crossings, range 6-13, for both the A$\mathrm{A}$ and $\mathrm{A}-\mathrm{CFC}$ groups, no difference between the two groups) 
A
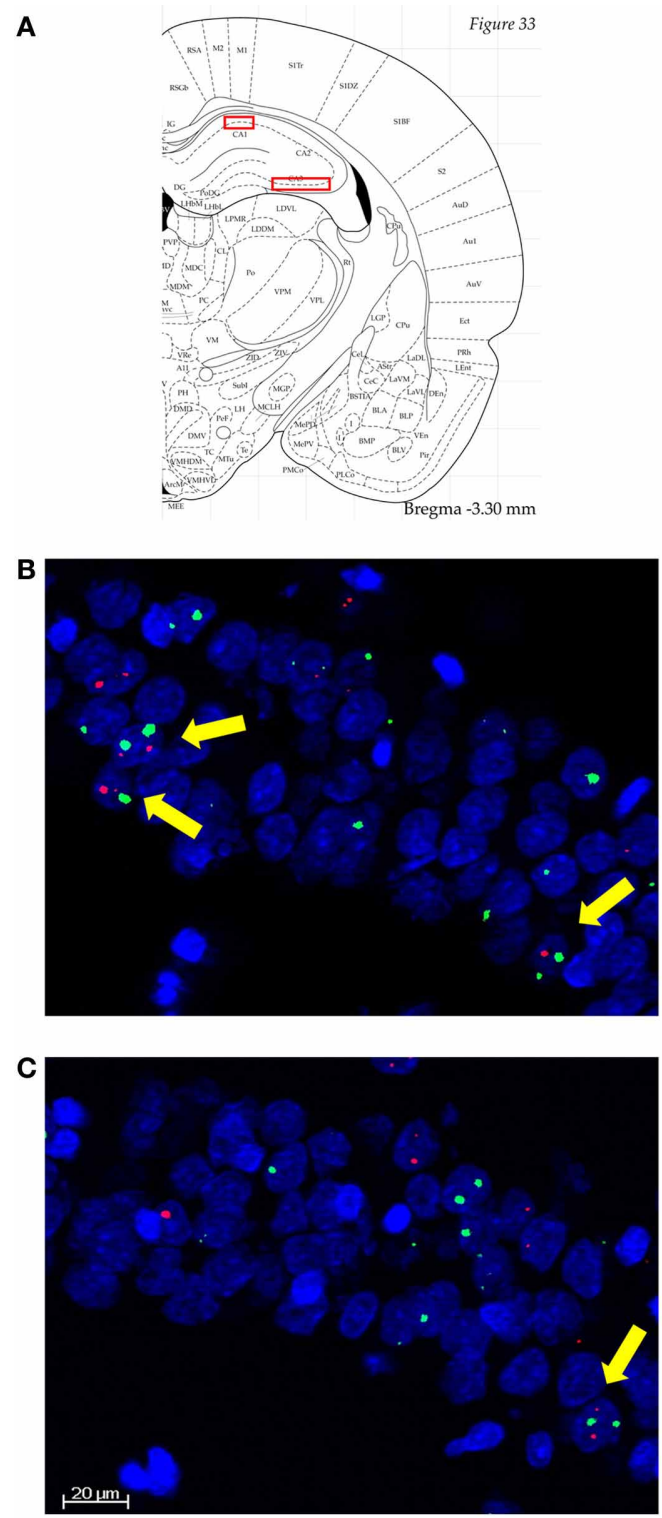

FIGURE 2 | (A) and (D) Diagrammatic representation of the approximate anatomical locations from which the analyzed images were collected (Paxinos and Watson, 4th Edn, Academic Press, San Diego, 1998). Septal/dorsal CA1 (dCA1), temporal/ventral CA1 (vCA1), and vCA3 were single stacks, while dCA3 were mosaics through dCA3b.

(B)-(F) Representative images from dCA1 of an A-A rat (B); dCA1 of an
D

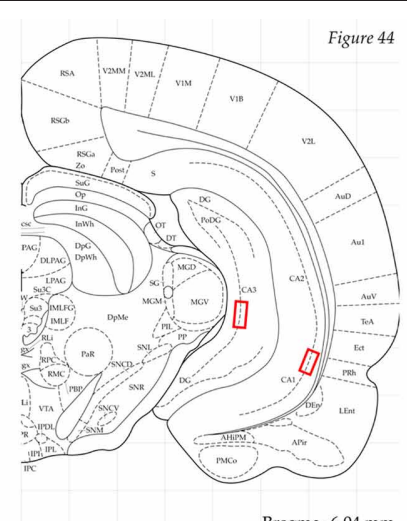

E

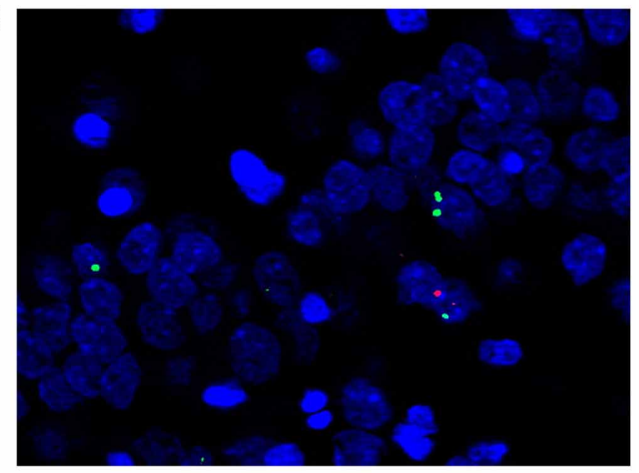

$\mathbf{F}$

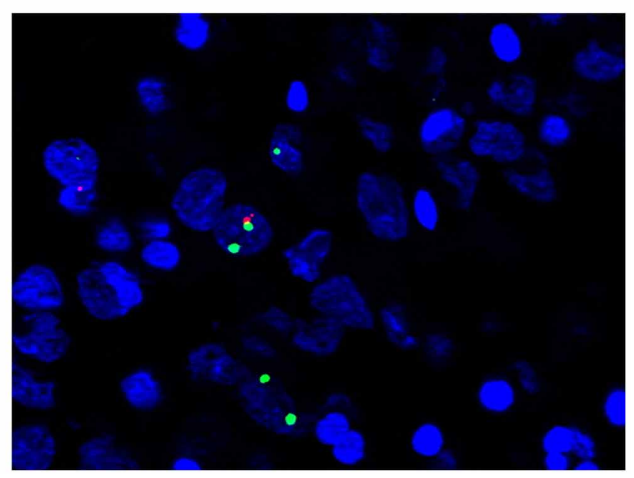

A-CFC rat (C); vCA1 of an A-A rat (E); and vCA1 of an A-CFC rat (F). ArC is in red, $\mathrm{H} 1 \mathrm{a}$ is in green, and nuclei are in blue. Scale bar is $20 \mu \mathrm{m}$. All images are $3 \mu \mathrm{m}$ thick. Note the higher number of neurons with Arc/H1a foci of transcription, to which yellow arrows point, in the A-A compared to A-CFC rats. The images also illustrate the lower percentage of IEG-expressing neurons in the VCA1, compared to the dCA1. and virtually no freezing. A-A rats showed similar behavioral patterns during their second visit to the same place. While ACFC rats did not show freezing behavior before the delivery of the two foot shocks, there was robust post-shock freezing compared to the freezing displayed by the A-A rats during the same period of time $\left[F_{(1,10)}=226.38, p<0.0001\right.$, Figure 1B $]$. Thus, A-CFC rats acquired robust contextual fear conditioning, as evidenced by their continued display of high levels of fear when the aversive stimulus itself was no longer present. Such CFC training also resulted in long-lasting memory for the event: $\mathrm{A}-\mathrm{CFC}$ rats tested $24 \mathrm{~h}$ later showed significantly more freezing than A-A rats (mean $62 \%$ vs. $2 \%$, respectively, $F_{(1,10)}=33.18$, $p<0.001)$.

\section{PAIRING FOOT SHOCK WITH SPATIAL STIMULI INDUCED A LARGE DECREASE IN THE SIZE OF DORSAL/SEPTAL CA1 (dCA1) NEURONAL ENSEMBLES EXPRESSING PLASTICITY-RELATED IMMEDIATE-EARLY GENES (IEGs)}

Images collected from dCA1 (Figure 2A) revealed that both spatial exploration (Figure 2B) and fear conditioning in the same context (Figure 2C) induced significant expression of Arc and $H 1 a$. While caged control rats had a very low percentage of $H 1 a+$ 
or Arc + cells (1\% and 3\%, respectively), Event 1 induced similarly high IEG expression in both A-A and A-CFC rats (Figure 3A). Visiting the same place a second time led to a decrease in the size of IEG+ ensembles (main effect of Event: $F_{(1,10)}=38.88, p<$ $0.0001)$. The decrease was relatively mild in the A-A group ( $p=$ $0.047)$ and very pronounced in the A-CFC group $(p=0.001)$. The CFC training appears to account for the decreased ensemble size in the A-CFC group, as revealed by a significant Event $\times$ Group interaction $\left[F_{(1,10)}=5.24, p<0.05\right]$ and a significant difference between the A-A and A-CFC groups during Event 2 $(p=0.018)$. The decrease could not be explained by the fact that the A-CFC rats were moving less and showing more freezing behavior, because there was no correlation between the percentage of cells activated during the CFC training (Arc+ neurons) and the number of crossings during the training $(b=-0.06$, $R^{2}=0.24$, ns); nor was there a correlation between the number of crossings during the first exploration and the percentage of $\mathrm{H} 1 \mathrm{a}+$ neurons $\left(b=+0.09, R^{2}=0.007, \mathrm{~ns}\right)$. The overall proportions of neurons expressing $\mathrm{Arc} / \mathrm{H} 1 \mathrm{a}$ during each event was smaller than previously observed with the catFISH method (Guzowski et al., 1999; Vazdarjanova et al., 2002, 2006; Vazdarjanova and Guzowski, 2004; Ramírez-Amaya et al., 2005) which is likely due to the much smaller size of the current apparatus $(x, y$ dimensions: $50 \times 10 \mathrm{~cm}$ ), with fewer spatial cues, than in the referenced publications (i.e., $61 \times 61 \mathrm{~cm}$ ).

\section{FEAR-CONDITIONING-INDUCED PARTIAL "REMAPPING" IN dCA1}

Not only were fewer dCA1 neurons activated during CFC, compared to exploring the same place without the aversive event, but the majority of the CFC-activated neurons were different from those activated by exploring the place alone: the overlap score for dCA1 in A-CFC rats was significantly smaller than the overlap score of A-A rats (Figure 3B, $F_{(1,10)}=5.00, p<0.05$ ). This partial "remapping," to borrow a term from neuroelectrophysiology, is not a function of the decreased size of the neuronal ensembles during CFC, because the overlap score is adjusted for the smaller of the two behavioral events (see "Materials and Methods"). Additionally, only $23.1 \%$ of the cells activated during Event 1 ( $\mathrm{H} 1 \mathrm{a}+$ cells) were also activated during Event 2 in the A-CFC group (Arc+/H1a+ cells), compared to $44.2 \%$ for the A-A group $\left[F_{(1,10)}=15.31, p<0.01\right]$. Graphically, the relationships between size and overlap of the ensembles activated in the first and second event are illustrated with Venn diagrams in Figure 3C. Note that although the overall percentage of IEG+ cells activated by both events is similar for the A-A and A-CFC groups, there is a big difference in the overlap. This change in overlap does not appear to be a simple reflection of experiencing a foot shock, because foot shock alone induced Arc in very few dCA1 neurons ( $4 \%$ vs. $3 \%$ in caged controls).

\section{FEAR-CONDITIONING-INDUCED CHANGES WERE LESS PRONOUNCED IN dCA3}

Fear-conditioning-induced changes in dCA3 ensembles were similar, but less pronounced, than those seen in dCA1. The ensemble size during the second event was smaller than that of the first event for both the A-A and A-CFC groups (Event effect: $F_{(1,10)}=$ $36.78, p<0.0001$; and only a trend of a group effect $p=0.09$, Figure 4A). However, the neuronal ensemble activated by Event 2 was smaller in the A-CFC versus the A-A rats $(p<0.05)$. Additionally, compared to exploration alone, CFC activated fewer of the neurons activated by the first exploration $(\mathrm{A}-\mathrm{A}=50.1 \%$ vs. $\mathrm{A}-\mathrm{CFC}=31.1 \%, p=0.013$, Figure $4 \mathrm{C}$ ). The overlap score was

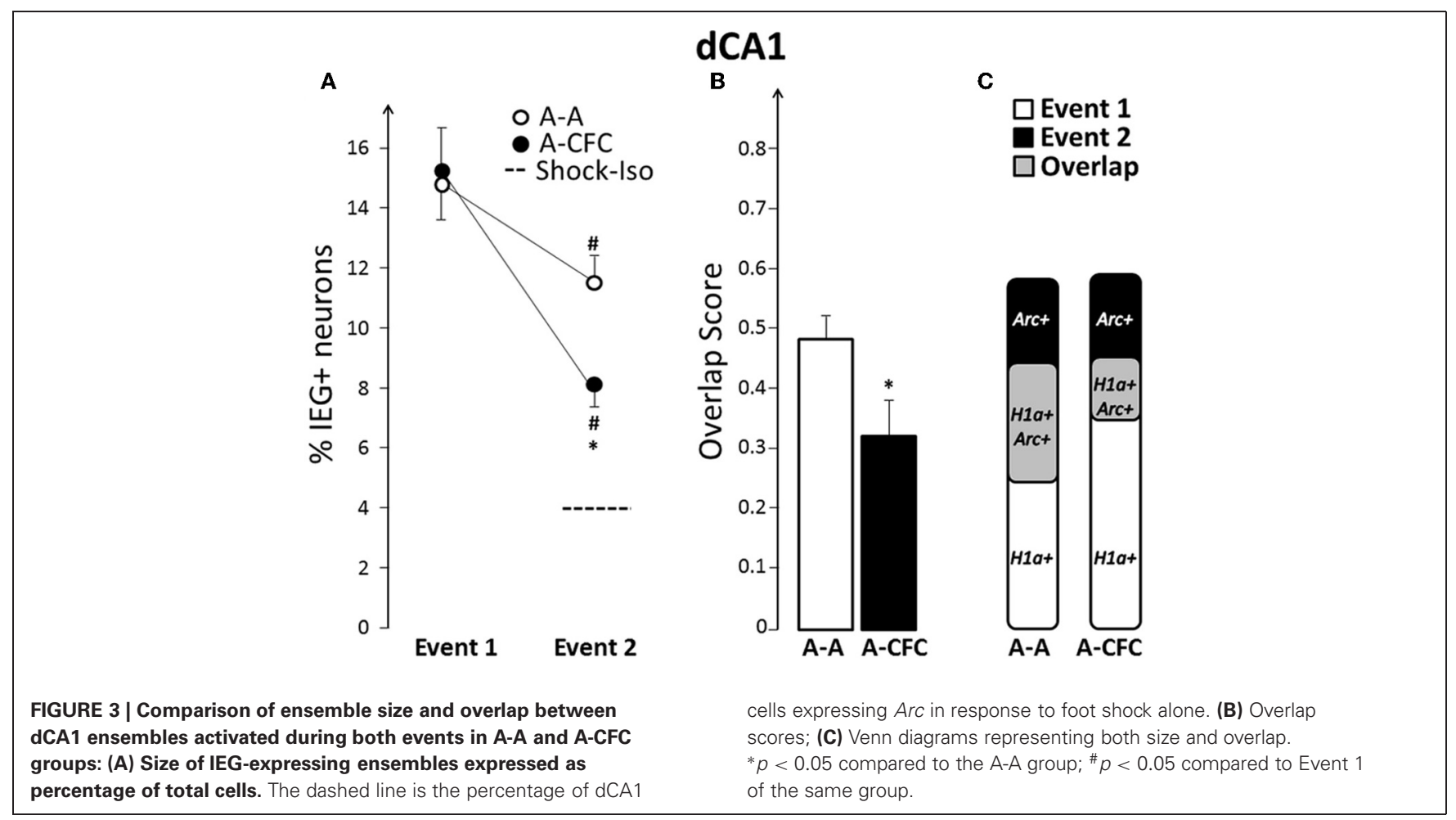




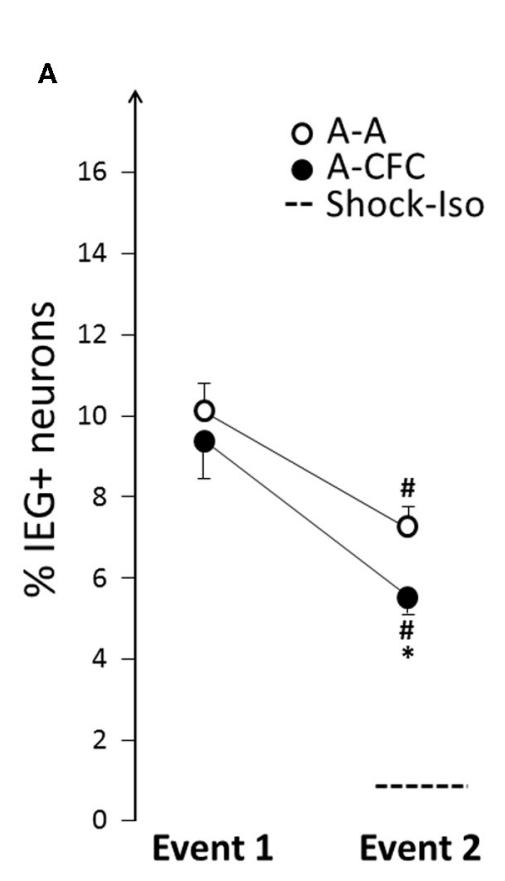

FIGURE 4 | Comparison of ensemble size and overlap between dCA3 ensembles activated during both events in A-A and A-CFC groups: (A) Size of IEG-expressing ensembles expressed as percentage of total cells. The dashed line is the percentage of

\section{dCA3}

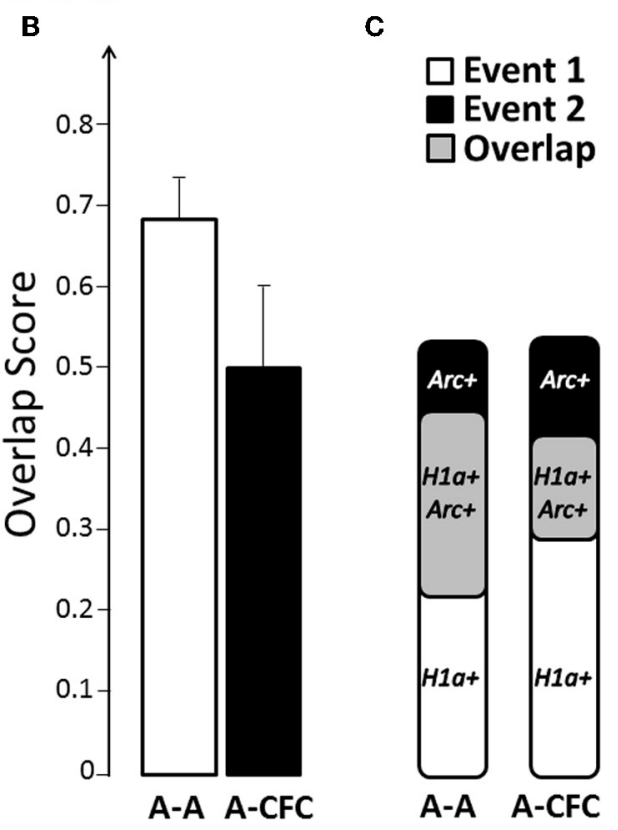

also decreased for the A-CFC group (Figure 4B), although it did not reach statistical significance due to a high overlap score in one $\mathrm{A}-\mathrm{CFC}$ rat (without this rat, $p=0.028$ ). Interestingly, the same rat had the lowest overlap score in dCA1. Such negative correlation between overlap scores in the dCA1 and dCA3 was observed for the entire A-CFC group $\left(b=-0.46, R^{2}=0.65, p=0.05\right)$, while no correlation was present in the A-A group $(b=+0.48$, $R^{2}=0.40, p=0.18$ ).

\section{NO CFC-INDUCED CHANGES IN SIZE OR OVERLAP IN vCA1}

On the basis of findings that functional integrity of, or plasticity in, the ventral hippocampus influences fear conditioning (Zhang et al., 2001; Maren and Holt, 2004; Hunsaker and Kesner, 2008); we hypothesized that there will be a more pronounced change in size and/or overlap in vCA1 and vCA3, compared to their dorsal counterparts. In contrast to this hypothesis, there was no difference in either the ensemble size (group effect: $F_{(1,10)}=2.76$, $\mathrm{ns})$, or overlap $\left[F_{(1,10)}=0.23, \mathrm{~ns}\right]$ between A-A and A-CFC rats (Figure 5).

\section{FEAR-CONDITIONING-INDUCED CHANGES IN OVERLAP IN vCA3}

In contrast to vCA1, vCA3 showed a significant decrease in the overlap score in the A-CFC, versus the A-A rats $\left[F_{(1,10)}=\right.$ 10.90, $p<0.01$; Figures $6 \mathbf{B}$ and $\mathbf{C}]$. This decrease occurred even though the ensemble size was similar to that of the A-A group for both events (Figure 6A). For both groups there was a significant decrease of the ensemble size during the second event, although this decrease was not due to fear conditioning (main effect of Event: $F_{(1,10)}=34.00, p<0.001$; no effect of Group or Group $\times$ Event interaction). However, fear conditioning disrupted a strong correlation between the ensemble size in dCA1 and vCA3 that emerged during exploration: there was a strong correlation between ensemble size in dCA1 and vCA3 in the A-A group $\left(b=+1.43, R^{2}=0.82, p<0.01\right)$ and no correlation in the A-CFC group $\left(b=-0.58, R^{2}=0.03\right)$. The ensemble size in vCA3 was not correlated with the ensemble size of vCA1 for either behavioral group $\left(R^{2}<0.20\right)$.

\section{DISCUSSION}

The research presented here tested two main hypotheses: (1) that conditioning fear to a place induces plasticity-related gene expression in the rodent hippocampus that is qualitatively different than that evoked by exploring the same place; and (2) that fear-conditioning-induced changes will occur preferentially in the temporal/ventral, but not septal/dorsal hippocampus. The results are congruent with the former, but not the latter hypothesis: different ensembles of cells expressing plasticity-related IEGs were observed when rats explored a place vs. when they received fear conditioning in that same place. These differences were detectable along the septo-temporal axis of the hippocampus, with the most notable effect of fear conditioning seen in the dorsal CA1 and ventral CA3. Specifically: (1) in dCA1, there was both a CFC-related decrease of ensemble size and overlap between IEG-expressing ensembles from both events in A-CFC, compared to A-A rats; (2) in dCA3, there was only a decrease in the ensemble size during the $\mathrm{CFC}$ and a statistically non-significant decrease in overlap for the A-CFC rats; (3) in vCA1, neither differences in ensemble size nor overlap were noted; (4) in vCA3, A-CFC rats 


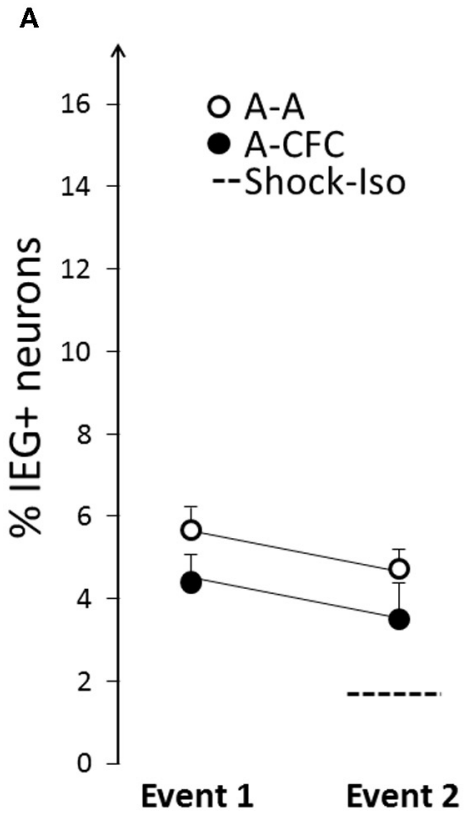

FIGURE 5 | Comparison of ensemble size and overlap between vCA1 ensembles activated during both events in A-A and A-CFC groups: (A) Size of IEG-expressing ensembles expressed as percentage of

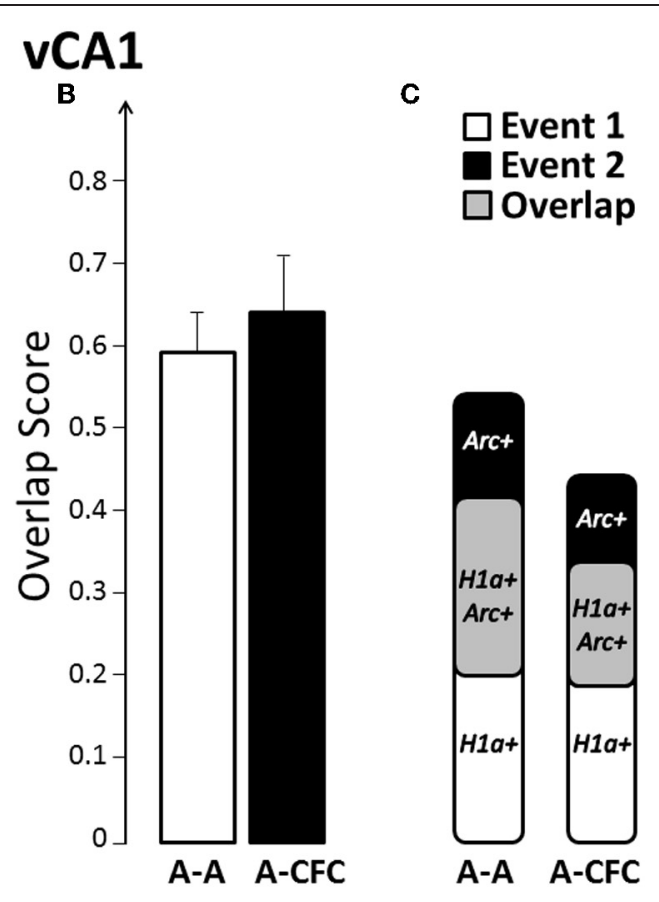

total cells. The dashed line is the percentage of vCA1 cells expressing Arc in response to foot shock alone. (B) Overlap scores; (C) Venn diagrams representing both size and overlap.

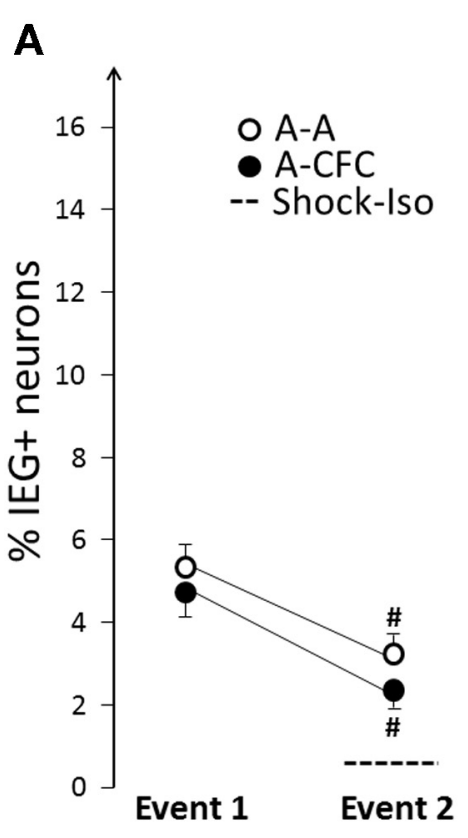

FIGURE 6 | Comparison of ensemble size and overlap between vCA3 ensembles activated during both events in A-A and A-CFC groups: (A) Size of IEG-expressing ensembles expressed as percentage of total cells. The dashed line is the percentage of vCA3

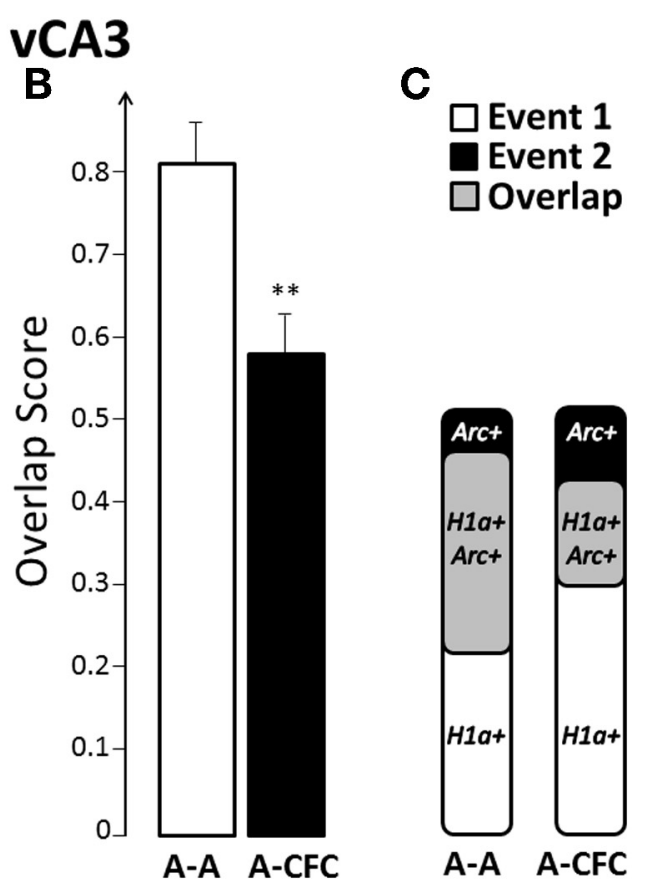

cells expressing Arc in response to foot shock alone. (B) Overlap scores; (C) Venn diagrams representing both size and overlap. ${ }^{* *} p<0.01$ compared to the A-A group; $\# p<0.05$ compared to Event 1 of the same group. 
had a significant decrease in overlap compared to A-A rats. Thus, an emotionally aversive event is represented with a pattern of plasticity-related gene expression along the septo-temporal axis of the hippocampus that is distinct from that elicited by spatial exploration alone.

\section{CONSIDERATIONS OF NOMENCLATURE}

While there has been little ambiguity as to the anatomical location of the term dorsal/septal hippocampus, what has been referred to as ventral/temporal hippocampus varies significantly in the literature, depending on how many divisions are included and what is used as relative location markers. Additionally, recent accounts have identified dorsal, intermediate, ventral and ventral-ventral divisions based on a combination of molecular markers (reviewed in Fanselow and Dong, 2010). Our choice of imaging fields from the ventral part of the hippocampus (Figure 2) was based on the projection patterns of the BLA (Pikkarainen et al., 1999; Petrovich et al., 2001), which cover the border of what would be considered intermediate and ventral hippocampus, based on a classification derived from a combined location/molecular markers perspective (Thompson et al., 2008; Dong et al., 2009). The BLA is involved in emotional memory and influences hippocampal plasticity in the dorsal hippocampus (McGaugh, 2004; Nakao et al., 2004). This likely occurs indirectly through projections to the lateral entorhinal cortex (Pikkarainen and Pitkänen, 2001), suggesting that direct BLA projections to the more ventral parts of the hippocampus could influence encoding of emotional events by that region. Experiments that are testing this hypothesis are currently underway. The ventral regions that we analyzed also correspond to those in which protein synthesis is necessary for proper consolidation of fear conditioning (Rudy and MatusAmat, 2005).

\section{IEG EXPRESSION IS NOT A MEASURE OF LOCOMOTION}

One of the main observations in the study is that there is a notable decrease in the size of IEG+ neuronal ensemble in several hippocampal regions during CFC. One could argue that this decrease in the size of IEG+ ensembles results from the decreased locomotion observed in the A-CFC group, compared to the control group that explored the apparatus twice without foot shock (A-A group). However, there was no correlation between the number of crossings and $\mathrm{Arc} / \mathrm{H} 1 \mathrm{a}$ expression, showing that suppressed locomotion cannot account for the decrease in IEG ensemble size. This is consistent with an increasing body of evidence which suggests that Arc and HIa are markers of plasticity and not neuronal activity, per se (Kelly and Deadwyler, 2003; Vazdarjanova and Guzowski, 2004; Guzowski et al., 2006; Carpenter-Hyland et al., 2010; McCurry et al., 2010). Therefore, our findings suggest that $\mathrm{CFC}$ reduces the number of dCA1 and dCA3 neurons undergoing plasticity during the aversive experience and does not simply reflect decreased locomotion. The decreased ensemble size may result from any of a number of reasons, such as suppressed plasticity in the hippocampus due to elevated levels of stress hormones during CFC, sped-up consolidation, or some other emotion-influenced process. Suppressed plasticity is an unlikely explanation, because stress hormones released from the adrenals in response to a stressor either enhance Arc expression: norepinephrine in the BLA, in concentrations that enhance memory, increases hippocampal Arc (McIntyre et al., 2005); or, as is the case with glucocorticoid levels in the hippocampus, are significantly elevated above baseline at $30 \mathrm{~min}$ (Thoeringer et al., 2007), which is much longer than 2 min-the time period required to influence Arc expression. Sped-up consolidation is a plausible explanation because in the course of spatial memory consolidation the size of Arc+ neuronal ensembles in the hippocampus and parietal cortex activated during learning shrinks in half (Ramírez-Amaya et al., 2005). Additionally, when memories are well-consolidated, the size of Arc + neuronal ensembles is significantly smaller than immediately after memory acquisition (Carpenter-Hyland et al., 2010).

The lack of correlation between Arc/H1a expression and locomotion is consistent with previous findings showing that Arc is a marker of long-term plasticity and memory and not a marker of acquisition; Arc protein is involved in memory consolidation and not acquisition (Guzowski et al., 2000; Plath et al., 2006; Wang et al., 2006; Ploski et al., 2008; Holloway and McIntyre, 2011). Therefore, our findings should be interpreted as affecting long-term memory processes and not memory acquisition.

\section{THE DORSAL HIPPOCAMPUS ENGAGES DIFFERENT IEG+ NEURONAL ENSEMBLES WHEN A SPATIAL CONTEXT IS EXPLORED ALONE AND WHEN IT IS ASSOCIATED WITH AN EMOTIONAL EVENT}

The fear conditioning training induced robust freezing, both immediately and $24 \mathrm{~h}$ after training, showing that, in the A-CFC but not the A-A group, the spatial context was associated with the fear-eliciting stimulus, foot shock. The CFC training also decreased the relative proportion of IEG-expressing cells in both the dCA1 and dCA3 that would normally re-express Arc and $\mathrm{H} 1 \mathrm{a}$ when a novel place is visited for a second time, as illustrated on Figures 3C and 4C. The differences in ensemble size and overlap between the A-A and A-CFC groups are likely due to differences in what the two groups experienced during the second event: exploring the context vs. associating it with foot shock, because the "where" and "when" parts of their experiences were matched. It is important to note that experiencing foot shock alone, without associating it with the context, could not explain the findings. Administering a shock without giving a chance for the rats to form a representation of the spatial context, a.k.a. "immediate shock" training, is unable to support CFC memory (Fanselow, 1980). We found no evidence that administering such immediate shock induces any significant IEG expression. Even if footshock induced Arc expression in the dorsal hippocampus, it should lead to a larger ensemble size during CFC, not smaller, as our data showed. Previous findings of increased IEG expression in an immediate shock group (Lonergan et al., 2010) may be related to the subsequent learning that occurred ("I got shocked, although I don't know exactly where") as evidenced by enhanced exploratory and burrowing behavior that occurs when rats are returned to their home cages after immediate footshock. To prevent this additional learning, we anesthetized the immediate shock rats immediately after receiving foot shock. Such treatment does not stop already initiated transcription, but prevents initiation of transcription under anesthesia (unpublished observations from our laboratory). 
These findings suggest that the dorsal hippocampus is involved in encoding emotional memories, in addition to encoding other types of episodic memory, and advance the idea that it is part of a larger memory system of brain regions that includes the basolateral and central amygdala, and the rostral anterior cingulate cortex (Maren, 2003; McGaugh, 2004; Rodrigues et al., 2004; Malin and McGaugh, 2006; Matus-Amat et al., 2007; Walker and Davis, 2008; Holloway and McIntyre, 2011). The findings also extend previous research showing that the dorsal hippocampus is necessary for single trial learning (Morris, 2001; Kesner, 2007), including single trial contextual fear conditioning (Wiltgen et al., 2006), by showing that the dorsal hippocampus creates qualitatively different representations of a context that is experienced with and without a fear-eliciting stimulus.

Although both dCA1 and dCA3 showed conditioning-induced changes, dCA1 also had a lower overlap in the A-A condition (Figures 3B and 4B). This observation can reflect a hypothesized role of dCA1 in encoding the temporal and sequence dimensions of episodic memories (Hunsaker et al., 2008; Farovik et al., 2010), as the two explorations of the same place (A-A condition) differ mostly along the temporal domain. This interpretation also can explain why in the present study we observed a smaller overlap in the A-A rats than what we have observed in the past: the temporal difference between the two events may have exerted a relatively larger influence than the spatial cues which were fewer than those used in previous investigations (Vazdarjanova et al., 2002; Vazdarjanova and Guzowski, 2004; Ramírez-Amaya et al., 2005). The fact that dCA3, compared to dCA1, had a less pronounced decrease in overlap in the A-CFC rats can reflect the computational characteristics of dCA3 in respect to pattern completion and pattern separation which have been evoked to explain differences in electrophysiological activity and IEG expression during spatial learning (Lee et al., 2004; Leutgeb et al., 2004; Vazdarjanova and Guzowski, 2004; Rolls and Kesner, 2006).

These findings were made possible because of the power of within animal experimental design combined with the temporal resolution of $A r c$ and $H 1 a$ expression visualized using the Arc/H1a catFISH method. Simply measuring the mRNA or protein levels of IEGs or other plasticity-related molecules would not have revealed the differences between the A-A and A-CFC groups, because the combined percentage of neurons with IEG expression from both events is similar in both groups. Indeed, no difference was reported for Arc protein levels in the dorsal hippocampus between a group that explored a place and a group that received fear conditioning in that place (Lonergan et al., 2010). However, we report striking differences in overlap showing that, at a network level, the same place is encoded by demonstrably different neuronal ensembles

\section{REFERENCES}

Babb, S. J., and Crystal, J. D. (2006). Episodic-like memory in the rat. Curr. Biol. 16, 1317-1321.

Barnes, C. A., McNaughton, B. L., Mizumori, S. J., Leonard, B. W., and Lin, L. H. (1990).
Comparison of spatial and temporal characteristics of neuronal activity in sequential stages of hippocampal processing. Prog. Brain Res. 83, 287-300.

Bast, T. (2011). The hippocampal learning-behavior translation and

when it is experienced alone vs. when it is associated with an aversive event.

\section{DIFFERENCES IN FEAR-CONDITIONING-INDUCED IEG EXPRESSION ALONG THE SEPTOTEMPORAL AXIS OF THE HIPPOCAMPUS}

Evidence of functional dissociations along the septotemporal axis of the hippocampus for spatial tasks has long been known (Hock and Bunsey, 1998; Moser and Moser, 1998; Hunsaker et al., 2008; Bast et al., 2009). Arc expression patterns during retrieval of spatial memory have also been documented (Gusev et al., 2005). Furthermore, lesions, blocking NMDA receptors, or blocking protein synthesis in the ventral hippocampus all impair longterm, but not short-term, memory for fear conditioning, while such manipulations of the dorsal hippocampus have less consistent effects (Zhang et al., 2001; Maren and Holt, 2004; Rudy and Matus-Amat, 2005; Rogers et al., 2006; Yoon and Otto, 2007). Evidence that ventral hippocampal lesions impair fear and anxiety behaviors (Kjelstrup et al., 2002; Blanchard et al., 2005), and evidence that amygdala-hippocampal projections terminate heavily in this region, led to the hypothesis that fear-conditioninginduced changes in IEG expression will be more notable in the ventral, compared to the dorsal hippocampus. Our data does not support this hypothesis: vCA1 did not show fear-conditioninginduced changes, while vCA3 did show changes, along with dCA1 and dCA3. The data suggest that both dorsal hippocampus and vCA3 may participate in encoding into long-term memory fearconditioning-induced associations, in addition to encoding other information, i.e., spatial and temporal information, because the changes in A-CFC rats are beyond the changes observed in A-A rats. This interpretation is consistent with findings that ventral/intermediate hippocampus is necessary for spatial memory (Ferbinteanu et al., 2003; Rudy and Matus-Amat, 2005), as well as long-term memory of contextual fear (Hunsaker and Kesner, 2008), and suggests that ventral hippocampus, like dorsal hippocampus, carries out associative functions for ongoing events, including spatial and emotional aspects, when present.

In summary, contextual fear conditioning, but not experiencing foot shock alone, produced a distinct pattern of long-term plasticity-related IEG expression along the septo-temporal axis of the hippocampus when compared to spatial learning in the same place. We propose that these differences reflect the acquisition of stimulus-stimulus associations, during fear conditioning, by the rodent hippocampus, in accordance with observations made in humans.

\section{ACKNOWLEDGMENTS}

This research was supported by R21MH083188 and NSF1138690. We thank the reviewers and Drs. Thane Plummer and David Blake for helpful comments on a previous version of the manuscript.

the functional significance of hippocampal dysfunction in schizophrenia. Curr. Opin. Neurobiol. 21, 492-501.

Bast, T., da Silva, B. M., and Morris, R. G. M. (2005). Distinct contributions of hippocampal NMDA and
AMPA receptors to encoding and retrieval of one-trial place memory. J. Neurosci. 25, 5845-5856.

Bast, T., Wilson, I. A., Witter, M. P., and Morris, R. G. M. (2009). From rapid place learning to behavioral performance: a key role for the 
intermediate hippocampus. PLoS Biol. 7:e1000089. doi: 10.1371/ journal.pbio. 1000089

Bechara, A., Tranel, D., Damasio, H., Adolphs, R., Rockland, C., and Damasio, A. R. (1995). Double dissociation of conditioning and declarative knowledge relative to the amygdala and hippocampus in humans. Science 269, 1115-1118.

Blanchard, D. C., Canteras, N. S., Markham, C. M., Pentkowski, N. S., and Blanchard, R. J. (2005). Lesions of structures showing FOS expression to cat presentation: effects on responsivity to a Cat, Cat odor, and nonpredator threat. Neurosci. Biobehav. Rev. 29, 1243-1253.

Bramham, C. R., Alme, M. N., Bittins, M., Kuipers, S. D., Nair, R. R., Pai, B., Panja, D., Schubert, M., Soule, J., Tiron, A., and Wibrand, K. (2010). The Arc of synaptic memory. Exp. Brain Res. 200, 125-140.

Cahill, L., and McGaugh, J. L. (1998). Mechanisms of emotional arousal and lasting declarative memory. Trends Neurosci. 21, 294-299.

Carpenter-Hyland, E. P., Plummer, T. K., Vazdarjanova, A., and Blake, D. T. (2010). Arc expression and neuroplasticity in primary auditory cortex during initial learning are inversely related to neural activity. Proc. Natl. Acad. Sci. U.S.A. 107, 14828-14832.

Chen, G., Wang, L. P., and Tsien, J. Z. (2009). Neural population-level memory traces in the mouse hippocampus. PLoS ONE 4:e8256. doi: 10.1371/journal.pone.0008256

Clayton, N. S., Salwiczek, L. H., and Dickinson, A. (2007). Episodic memory. Curr. Biol. 17, R189-R191.

Clayton, N. S., and Dickinson, A. (1998). Episodic-like memory during cache recovery by scrub jays. Nature 395, 272-274.

Dong, H.-W., Swanson, L. W., Chen, L., Fanselow, M. S., and Toga, A. W. (2009). Genomic-anatomic evidence for distinct functional domains in hippocampal field CA1. Proc. Natl. Acad. Sci. U.S.A. 106, 11794-11799.

Eichenbaum, H., Sauvage, M., Fortin, N., Komorowski, R., and Lipton, P. (2011). Towards a functional organization of episodic memory in the medial temporal lobe. Neurosci. Biobehav. Rev. doi: 10.1016/j. neubiorev.2011.07.006. [Epub ahead of print].

Fagni, L., Worley, P. F., and Ango, F. (2002). Homer as both a scaffold and transduction molecule. Sci. STKE 2002, re8.
Fanselow, M. S. (1980). Conditioned and unconditional components of post-shock freezing. Pavlov. J. Biol. Sci. 15, 177-182.

Fanselow, M. S., and Dong, H.-W. (2010). Are the dorsal and ventral hippocampus functionally distinct structures? Neuron 65, 7-19.

Farovik, A., Dupont, L. M., and Eichenbaum, H. (2010). Distinct roles for dorsal CA3 and CA1 in memory for sequential nonspatial events. Learn. Mem. 17, 12-17.

Ferbinteanu, J., Kennedy, P. J., and Shapiro, M. L. (2006). Episodic memory-from brain to mind. Hippocampus 16, 691-703.

Ferbinteanu, J., Ray, C., and McDonald, R. J. (2003). Both dorsal and ventral hippocampus contribute to spatial learning in Long-Evans rats. Neurosci. Lett. 345, 131-135.

Gusev, P. A., Cui, C., Alkon, D. L., and Gubin, A. N. (2005). Topography of Arc/Arg3.1 mRNA expression in the dorsal and ventral hippocampus induced by recent and remote spatial memory recall: dissociation of CA 3 and CA1 activation. J. Neurosci. 25, 9384-9397.

Guzowski, J. F., Lyford, G. L., Stevenson, G. D., Houston, F. P., McGaugh, J. L., Worley, P. F., and Barnes, C. A. (2000). Inhibition of activity-dependent arc protein expression in the rat hippocampus impairs the maintenance of long-term potentiation and the consolidation of longterm memory. J. Neurosci. 20, 3993-4001.

Guzowski, J. F., McNaughton, B. L., Barnes, C. A., and Worley, P. F. (1999). Environment-specific expression of the immediate-early gene Arc in hippocampal neuronal ensembles. Nat. Neurosci. 2, 1120-1124.

Guzowski, J. F., Miyashita, T., Chawla, M. K., Sanderson, J., Maes, L. I., Houston, F. P., Lipa, P., McNaughton, B. L., Worley, P. F., and Barnes, C. A. (2006). Recent behavioral history modifies coupling between cell activity and Arc gene transcription in hippocampal CA1 neurons. Proc. Natl. Acad. Sci. U.S.A. 103, 1077-1082.

Hock, B. J. Jr., and Bunsey, M. D. (1998). Differential effects of dorsal and ventral hippocampal lesions. J. Neurosci. 18, 7027-7032.

Holloway, C. M., and McIntyre, C. K. (2011). Post-training disruption of Arc protein expression in the anterior cingulate cortex impairs long-term memory for inhibitory avoidance training. Neurobiol. Learn. Mem. 95, 425-432.
Hunsaker, M. R., Fieldsted, P. M., Rosenberg, J. S., and Kesner, R. P. (2008). Dissociating the roles of dorsal and ventral CA1 for the temporal processing of spatial locations, visual objects, and odors. Behav. Neurosci. 122, 643-650.

Hunsaker, M. R., and Kesner, R. P. (2008). Dissociations across the dorsal-ventral axis of CA3 and CA1 for encoding and retrieval of contextual and auditory-cued fear. Neurobiol. Learn. Mem. 89, 61-69.

Kart-Teke, E., De Souza Silva, M. A., Huston, J. P., and Dere, E. (2006). Wistar rats show episodiclike memory for unique experiences. Neurobiol. Learn. Mem. 85, 173-182.

Kelly, M. P., and Deadwyler, S. A. (2003). Experience-dependent regulation of the immediate-early gene arc differs across brain regions. J. Neurosci. 23, 6443-6451.

Kesner, R. P. (2007). Behavioral functions of the CA3 subregion of the hippocampus. Learn. Mem. 14, 771-781.

Kjelstrup, K. G., Tuvnes, F. A., Steffenach, H.-A., Murison, R., Moser, E. I., and Moser, M.-B. (2002). Reduced fear expression after lesions of the ventral hippocampus. Proc. Natl. Acad. Sci. U.S.A. 99, 10825-10830.

Lee, I., Yoganarasimha, D., Rao, G., and Knierim, J. J. (2004). Comparison of population coherence of place cells in hippocampal subfields CA1 and CA3. Nature 430, 456-459.

Leutgeb, S., Leutgeb, J. K., Treves, A., Moser, M., and Moser, E. I. (2004). Distinct ensemble codes in hippocampal areas CA3 and CA1. Science 305, 1295-1298.

Li, J.-S., and Chao, Y.-S. (2008). Electrolytic lesions of dorsal CA3 impair episodic-like memory in rats. Neurobiol. Learn. Mem. 89, 192-198.

Li, J.-S., Hsiao, K.-Y., and Chen, W.-M. (2011). Effects of medial prefrontal cortex lesions in rats on the whatwhere-when memory of a fear conditioning event. Behav. Brain Res. 218, 94-98.

Lonergan, M. E., Gafford, G. M., Jarome, T. J., and Helmstetter, F. J. (2010). Time-dependent expression of Arc and zif268 after acquisition of fear conditioning. Neural Plast. 2010, 139891.

Malin, E. L., and McGaugh, J. L. (2006). Differential involvement of the hippocampus, anterior cingulate cortex, and basolateral amygdala in memory for context and footshock. Proc. Natl. Acad. Sci. U.S.A. 103, 1959-1963.
Maren, S. (2003). The amygdala, synaptic plasticity, and fear memory. Ann. N.Y. Acad. Sci. 985, 106-113.

Maren, S., and Holt, W. G. (2004). Hippocampus and Pavlovian fear conditioning in rats: muscimol infusions into the ventral, but not dorsal, hippocampus impair the acquisition of conditional freezing to an auditory conditional stimulus. Behav. Neurosci. 118, 97-110.

Matus-Amat, P., Higgins, E. A., Sprunger, D., Wright-Hardesty, K., and Rudy, J. W. (2007). The role of dorsal hippocampus and basolateral amygdala NMDA receptors in the acquisition and retrieval of context and contextual fear memories. Behav. Neurosci. 121, 721-731.

McCurry, C. L., Shepherd, J. D., Tropea, D., Wang, K. H., Bear, M. F., and Sur, M. (2010). Loss of Arc renders the visual cortex impervious to the effects of sensory experience or deprivation. Nat. Neurosci. 13, 450-457.

McGaugh, J. L. (2004). The amygdala modulates the consolidation of memories of emotionally arousing experiences. Annu. Rev. Neurosci. 27, 1-28.

McIntyre, C. K., Miyashita, T., Setlow, B., Marjon, K. D., Steward, O., Guzowski, J. F., and McGaugh, J. L. (2005). Memory-influencing intra-basolateral amygdala drug infusions modulate expression of Arc protein in the hippocampus. Proc. Natl. Acad. Sci. U.S.A. 102, 10718-10723.

McNaughton, B. L., Barnes, C. A., Meltzer, J., and Sutherland, R. J. (1989). Hippocampal granule cells are necessary for normal spatial learning but not for spatiallyselective pyramidal cell discharge. Exp. Brain Res. 76, 485-496.

Moita, M. A. P., Rosis, S., Zhou, Y., LeDoux, J. E., and Blair, H. T. (2004). Putting fear in its place: remapping of hippocampal place cells during fear conditioning. J. Neurosci. 24, 7015-7023.

Morris, R. G. M. (2001). Episodiclike memory in animals: psychological criteria, neural mechanisms and the value of episodic-like tasks to investigate animal models of neurodegenerative disease. Philos. Trans. R. Soc. Lond. B Biol. Sci. 356, 1453-1465.

Moser, M. B., and Moser, E. I. (1998). Functional differentiation in the hippocampus. Hippocampus 8, 608-619.

Nakao, K., Matsuyama, K., Matsuki, N., and Ikegaya, Y. (2004). Amygdala 
stimulation modulates hippocampal synaptic plasticity. Proc. Natl. Acad. Sci. U.S.A. 101, 14270-14275.

O'Brien, J., and Sutherland, R. J. (2007). Evidence for episodic memory in a pavlovian conditioning procedure in rats. Hippocampus 17, 1149-1152.

Pavlov, I. P. (1927). Conditioned Reflexes: An Investigation of the Physiological Activity of the Cerebral Cortex. (Translated and edited by G. V. Anrep). London: Oxford University Press.

Petrovich, G. D., Canteras, N. S., and Swanson, L. W. (2001). Combinatorial amygdalar inputs to hippocampal domains and hypothalamic behavior systems. Brain Res. Rev. 38, 247-289.

Pikkarainen, M., and Pitkänen, A. (2001). Projections from the lateral, basal and accessory basal nuclei of the amygdala to the perirhinal and postrhinal cortices in rat. Cereb. Cortex 11, 1064-1082.

Pikkarainen, M., Rönkkö, S., Savander, V., Insausti, R., and Pitkänen, A. (1999). Projections from the lateral, basal, and accessory basal nuclei of the amygdala to the hippocampal formation in rat. J. Comp. Neurol. $403,229-260$.

Plath, N., Ohana, O., Dammermann, B., Errington, M. L., Schmitz, D., Gross, C., Mao, X., Engelsberg, A., Mahlke, C., Welzl, H., Kobalz, U., Stawrakakis, A., Fernandez, E., Waltereit, R., Bick-Sander, A., Therstappen, E., Cooke, S. F., Blanquet, V., Wurst, W., Salmen, B., Bösl, M. R., Lipp, H. P., Grant, S. G., Bliss, T. V., Wolfer, D. P., and Kuhl, D. (2006). Arc/Arg3.1 is essential for the consolidation of synaptic plasticity and memories. Neuron 52 , 437-444.

Ploski, J. E., Pierre, V. J., Smucny, J., Park, K., Monsey, M. S., Overeem, K. A., and Schafe, G. E. (2008). The activity-regulated cytoskeletalassociated protein (Arc/Arg3.1) is required for memory consolidation of pavlovian fear conditioning in the lateral amygdala. J. Neurosci. 28, 12383-12395.

Ramírez-Amaya, V., Vazdarjanova, A., Mikhael, D., Rosi, S., Worley,
P. F., and Barnes, C. A. (2005). Spatial exploration-induced Arc mRNA and protein expression: evidence for selective, networkspecific reactivation. J. Neurosci. 25 , 1761-1768.

Rodrigues, S. M., Schafe, G. E., and LeDoux, J. E. (2004). Molecular mechanisms underlying emotional learning and memory in the lateral amygdala. Neuron 44, 75-91.

Rogers, J. L., Hunsaker, M. R., and Kesner, R. P. (2006). Effects of ventral and dorsal CA1 subregional lesions on trace fear conditioning. Neurobiol. Learn. Mem. 86, 72-81.

Rolls, E. T., and Kesner, R. P. (2006). A computational theory of hippocampal function, and empirical tests of the theory. Prog. Neurobiol. 79, $1-48$.

Rudy, J. W., and Matus-Amat, P. (2005). The ventral hippocampus supports a memory representation of context and contextual fear conditioning: implications for a unitary function of the hippocampus. Behav. Neurosci. 119, 154-163.

Sauvage, M. M., Fortin, N. J., Owens, C. B., Yonelinas, A. P., and Eichenbaum, H. (2008). Recognition memory: opposite effects of hippocampal damage on recollection and familiarity. Nat. Neurosci. 11, 16-18.

Szumlinski, K. K., Kalivas, P. W., and Worley, P. F. (2006). Homer proteins: implications for neuropsychiatric disorders. Curr. Opin. Neurobiol. 16, 251-257.

Thoeringer, C. K., Sillaber, I., Roedel, A., Erhardt, A., Mueller, M. B., Ohl, F., Holsboer, F., and Keck, M. E. (2007). The temporal dynamics of intrahippocampal corticosterone in response to stress-related stimuli with different emotional and physical load: an in vivo microdialysis study in C57BL/6 and DBA/2 inbred mice. Psychoneuroendocrinology 32 , 746-757.

Thompson, C. L., Pathak, S. D., Jeromin, A., Ng, L. L., MacPherson, C. R., Mortrud, M. T., Cusick, A., Riley, Z. L., Sunkin, S. M., Bernard, A., Puchalski, R. B.,
Gage, F. H., Jones, A. R., Bajic, V. B., Hawrylycz, M. J., and Lein, E. S. (2008). Genomic anatomy of the hippocampus. Neuron 60 , 1010-1021.

Tolman, E. C. (1949). Purposive Behavior in Animals and Men. Berkeley, CA: University of California Press.

Vazdarjanova, A., and Guzowski, J. F. (2004). Differences in hippocampal neuronal population responses to modifications of an environmental context: evidence for distinct, yet complementary, functions of $\mathrm{CA} 3$ and CA1 ensembles. J. Neurosci. 24, 6489-6496.

Vazdarjanova, A., and McGaugh, J. L. (1998). Basolateral amygdala is not critical for cognitive memory of contextual fear conditioning. Proc. Natl. Acad. Sci. U.S.A. 95, 15003-15007.

Vazdarjanova, A., and McGaugh, J. L. (1999). Basolateral amygdala is involved in modulating consolidation of memory for classical fear conditioning. J. Neurosci. 19, 6615-6622.

Vazdarjanova, A., McNaughton, B. L., Barnes, C. A., Worley, P. F., and Guzowski, J. F. (2002). Experiencedependent coincident expression of the effector immediate-early genes arc and Homer la in hippocampal and neocortical neuronal networks. J. Neurosci. 22, 10067-10071.

Vazdarjanova, A., Ramirez-Amaya, V., Insel, N., Plummer, T. K., Rosi, S., Chowdhury, S., Mikhael, D., Worley, P. F., Guzowski, J. F., and Barnes, C. A. (2006). Spatial exploration induces ARC, a plasticity-related immediate-early gene, only in calcium/calmodulin-dependent protein kinase II-positive principal excitatory and inhibitory neurons of the rat forebrain. J. Comp. Neurol. 498, 317-329.

Walker, D. L., and Davis, M. (2008). Role of the extended amygdala in short-duration versus sustained fear: a tribute to Dr. Lennart Heimer. Brain Struct. Funct. 213, 29-42.

Wang, K. H., Majewska, A., Schummers, J., Farley, B., Hu,
C., Sur, M., and Tonegawa, S. (2006). In vivo two-photon imaging reveals a role of arc in enhancing orientation specificity in visual cortex. Cell 126, 389-402.

West, M. J., Slomianka, L., and Gundersen, H. J. (1991). Unbiased stereological estimation of the total number of neurons in thesubdivisions of the rat hippocampus using the optical fractionator. Anat. Rec. 231, 482-497.

Wiltgen, B. J., Sanders, M. J., Anagnostaras, S. G., Sage, J. R., and Fanselow, M. S. (2006). Context fear learning in the absence of the hippocampus. J. Neurosci. 26, 5484-5491.

Yoon, T., and Otto, T. (2007). Differential contributions of dorsal vs. ventral hippocampus to auditory trace fear conditioning. Neurobiol. Learn. Mem. 87, 464-475.

Zhang, W. N., Bast, T., and Feldon, J. (2001). The ventral hippocampus and fear conditioning in rats: different anterograde amnesias of fear after infusion of $\mathrm{N}$-methyl$\mathrm{D}$-aspartate or its noncompetitive antagonist MK-801 into the ventral hippocampus. Behav. Brain Res. 126, 159-174.

Conflict of Interest Statement: The authors declare that the research was conducted in the absence of any commercial or financial relationships that could be construed as a potential conflict of interest.

Received: 06 March 2012; paper pending published: 28 March 2012; accepted: 27 May 2012; published online: 14 June 2012.

Citation: Nalloor R, Bunting KM and Vazdarjanova A (2012) Encoding of emotion-paired spatial stimuli in the rodent hippocampus. Front. Behav. Neurosci. 6:27. doi: 10.3389/fnbeh. 2012.00027

Copyright $\odot 2012$ Nalloor, Bunting and Vazdarjanova. This is an open-access article distributed under the terms of the Creative Commons Attribution Non Commercial License, which permits noncommercial use, distribution, and reproduction in other forums, provided the original authors and source are credited. 